\title{
In Vitro Evaluation of the Flexural Strength of Different Temporary Crown Materials, After Thermocycling
}

\author{
Georges El Najjar ${ }^{1,3 *}$, Halal $\mathbf{R}^{2}$, Daou $\mathbf{M}^{3}$ and Zebouni $\mathrm{E}^{1}$ \\ ${ }^{1}$ Department of Fixed Prosthetics, Saint-Joseph University, Lebanon \\ ${ }^{2}$ Private Practice, Lebanon \\ ${ }^{3}$ Department of Pediatric Dentistry, Saint-Joseph University, Lebanon \\ *Corresponding Author: Georges El Najjar, Research Assistant, Department of \\ Fixed Prosthetics, Saint-Joseph University, Lebanon.
}

Received: July 17, 2021

Published: August 24, 2021

(C) All rights are reserved by Georges El

Najjar., et al.

\begin{abstract}
Objective of this Study: To study the variation of flexural strength as a function of time during an interval simulating a time span of a year in the mouth and determine whether the mechanical performance of the materials in question remains acceptable.

Materials and Methods: Three types of materials are used: bis-acrylic resin (Tempsmart ${ }^{\circledR}$ and Cooltemp ${ }^{\circledR}$ ), conventional PMMA (Unifast III ${ }^{\circledR}$ ) and composite resin (Revoteck LC ${ }^{\circledR}$ ). The flexural strength is evaluated. The samples undergo thermal cycling up to 10 000 cycles and are evaluated at different points in time.

Results: The bis-acrylic and conventional PMMA showed acceptable results throughout this study. The bis-acrylic material Tempsmart ${ }^{\circledR}$ showed the best values. The composite material Revoteck LC ${ }^{\circledR}$ has shown to be inadequate.

Conclusion: Among the tested materials, Tempsmart ${ }^{\circledR}$ is the most suited for long-term temporary restorations.

Keywords: Flexural Strength; Temporary Restoration; Bis-Acrylic Resin; Composite Resin; Conventional PMMA
\end{abstract}

\section{Abbreviations}

b: Width in Millimeters; Bis-GMA: Bisphenol A-Glycidyl Dimethacrylate; F: Maximum Load in Newton; h: Height in Millimeters; ISO: International Organization for Standardization; l: The Length in Millimeters; mm: Millimeter; MPa: Megapascal; nm: Nanometer; PEMA: Polyethymethacrylate; PMMA: Polymethymethacrylate; UDMA: Urethane dimethacrylate; $\mu \mathrm{m}$ : Micrometer; $\sigma$ : Flexural Strength in MPa

\section{Introduction}

A full prosthetic treatment includes many phases (laboratory fabrication, periodontal preparation ...) according to the Academy of Fixed Prosthodontics and is done over a mid to a long period of time [1]. This fact has made provisional restorations a key element to the success of the definitive restoration and the treatment overall.

The requirements for a successful temporary restoration, though downplayed at times, are very close to those of a definitive restoration [2]. According to Shillinburg, these requirements are pulpal protection, positional stability, occlusal function, ease of cleaning, non-impinging margin, strength, retention, and esthetics [3].

Several complications may arise during the phase of temporary treatment. The most prominent being marginal inaccuracies, frac- 
tures, and non-integrity of the external contour [4]. While the failure of the provisionals may occur at any point during the lifespan of a temporary restoration (fabrication, insertion, disinsertion, and function) it is important to note that when it does, it can negatively affect the remaining dental tissue, the health of the peridontium, and the functional and psychological well-being of the patient.

Fractures are a mechanical failure, a result of the propagation of a crack inside the material wrought on originally by surface flaw [1], a void in the material, inadequate thickness at the level of the connector or the preparation. Even in ideal manufacturing conditions, resin-based materials are by nature brittle, the fracture risk is always significant, hence it is important to always consider the flexural strength of the material [5].

The duration of use of temporary crowns may in some cases extend to 6 months, one year or even further, especially in cases of Vertical Dimension Alteration, Temporomandibular Joint Disorders, Orthodontics, Interim Implant Restorations and Bone Grafts. Most experimental studies limit the artificial ageing of the materials to a period of 6 months, which is insufficient to determine whether these materials' mechanical properties are adequate to fulfill their roles to the fullest extent in the complex cases mentioned beforehand.

\section{Objective of the Study}

The objective of this research is to study the variation of flexural strength as a function of time during an interval simulating a time span of a year in the mouth and determine whether the mechanical performance of the materials in question remains acceptable.

\section{Clinical Significance}

This study will allow the clinical practitioner to choose the most appropriate temporization material and determine a time period when the selected material's properties become inadequate and in need of replacing thus preventing complications.

\section{Materials and Methods}

List of materials and tools required

- A self-curing methyl methacrylate-based material (Unifast III by $\mathrm{GC}^{\circledR}$ )

- Two bis-acrylic resin-based materials (Tempsmart by $\mathrm{GC}^{\circledR}$ and Cooltemp by Coltene ${ }^{\circledR}$ )

- A composite-based material (Revotek LC by GC ${ }^{\circledR}$ )
- A curing light source (the Kerr Demiplus LED curing)

- $\quad$ Stainless steel mold

- 2 glass plates

- A thermocycler: Mechatronik SD thermocycler

- A universal testing machine: YLE universal testing machine.

\section{Experimental procedure}

Preparation of the specimen

Specimen preparation: A Stainless-Steel mold is prepared in order to produce the specimen in the form of bar (25 $\times 2 \times 2 \mathrm{~mm})$ according to EN ISO 4049;2009 (Figure 1).

\section{Inclusion criteria:}

- $\quad 25 \times 2 \times 2 \mathrm{~mm}$ bars

- No visible defects stemming from a lack of material (bubbles)

- $\quad$ Polished surface.

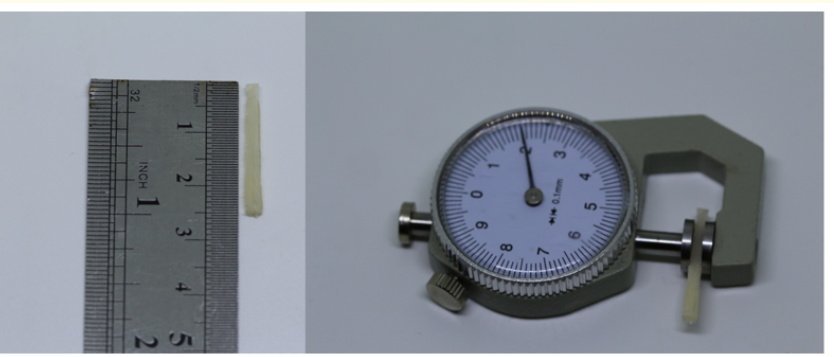

Figure 1: A display of the length and width of a specimen.

\section{Exclusion criteria}

- Visible defects as cracks or bubbles.

- Significant dimensional variations (The specimen were verified by a second operator).

Polymethymethacrylate samples

Before the preparation of the methyl methacrylate samples, the amount of powder ( $2 \mathrm{mg}$ ) is measured using a precision cup provided by the manufacturer and the acrylic liquid is dosed using a pipette $(0.5 \mathrm{~mL}$ capacity, $1 \mathrm{~mL}$ in total per $2 \mathrm{mg}$ of powder) (Figure 4). The stainless-steel mold is placed on the first glass plate. 


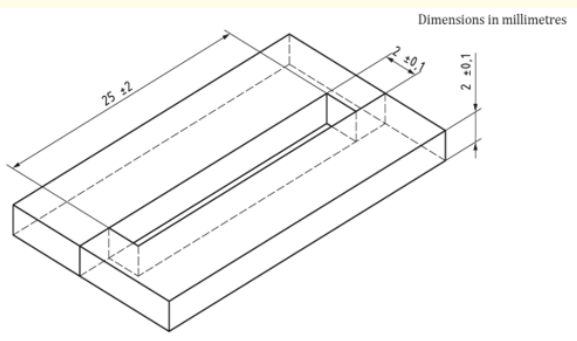

Figure 2: A schematic representation of a mold as indicated by ISO 4049:2009.

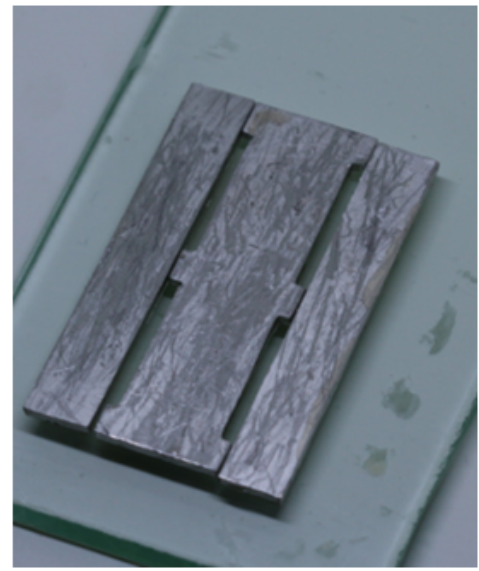

Figure 3: The mold used in this study.

The mixture is made by hand using a metal mixing spatula in a silicone cup. The mixture is inserted into the open pat of the mold. The larger quantity of excess is eliminated immediately by spatula, then the open part of the mold is covered with a glass plate, and the contraption is pressured and held together until the setting time is over (Figure 5). Following this, the specimen was polished using sandpaper (2400 grit).

\section{Bis-acryl samples}

The stainless-steel mold is placed on the first glass plate. The bis-acryl material (Figure 6) is mixed and inserted into the mold with the Ramitec syringe (3M). The larger quantity of excess is

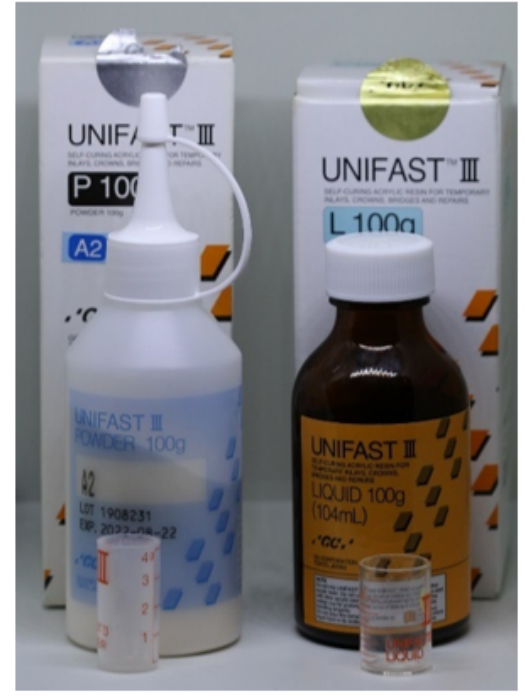

Figure 4: The acrylic resin Unifast $\mathrm{III}^{\circledR}$, the powder (left) and the liquid (right).

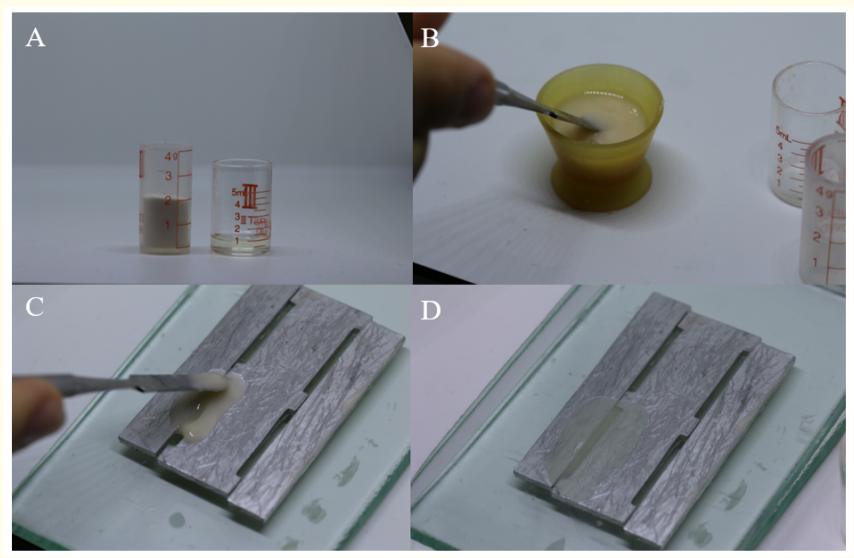

Figure 5: Fabrication of an acrylic resin specimen: A:dosage of powder and liquid, B: mixture, C: insertion into the mold, D: pressing of the second glass plate until setting.

eliminated immediately by spatula, then the open part of the mold is covered with a glass plate, and the contraption is pressured, held together and exposed to the curing light for 20 seconds each side 
using the Kerr Demiplus LED curing. After removal from the mold, the specimens are also exposed to 20 seconds of the curing light each side (Figure 7). Following this, the specimen was polished using sandpaper (2400 grit).

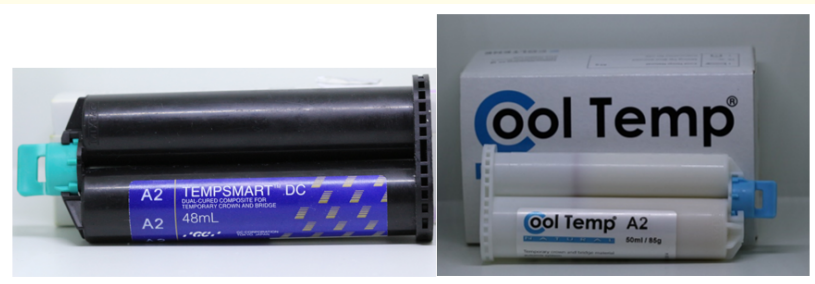

Figure 6: The Bis-acrylic materials Tempsmart ${ }^{\circledR}$ (left) and Cooltemp (right) ${ }^{\circledR}$.

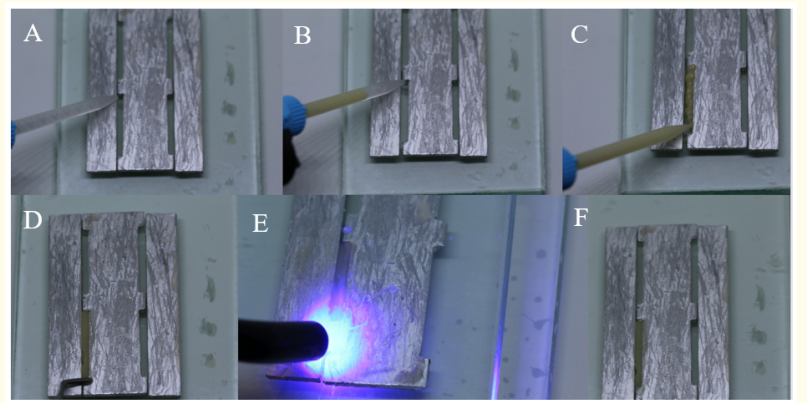

Figure 7: Fabrication of a bis-acrylic specimen : A: insertion of the mixing tip in the mold, B: mixture inside the mixing tip, C: insertion of the mixed resin into the mold, D: removal of excess, E: pressing of the second glass plate and photopolymerization, E: end result.

\section{Composite samples}

The stainless-steel mold is placed on the first glass plate. The composite (Figure 8) is cut using a spatula, then inserted into the mold. The second piece of glass is pressed against the mold, then set aside to remove all obvious excess using the spatula. The glass is pressed again by hand while using the $\operatorname{Kerr}^{\circledR}$ Demiplus LED curing light for 10 seconds, then 20 seconds as per the manufacturer's recommendations. Following this, the specimen is polished using sandpaper.

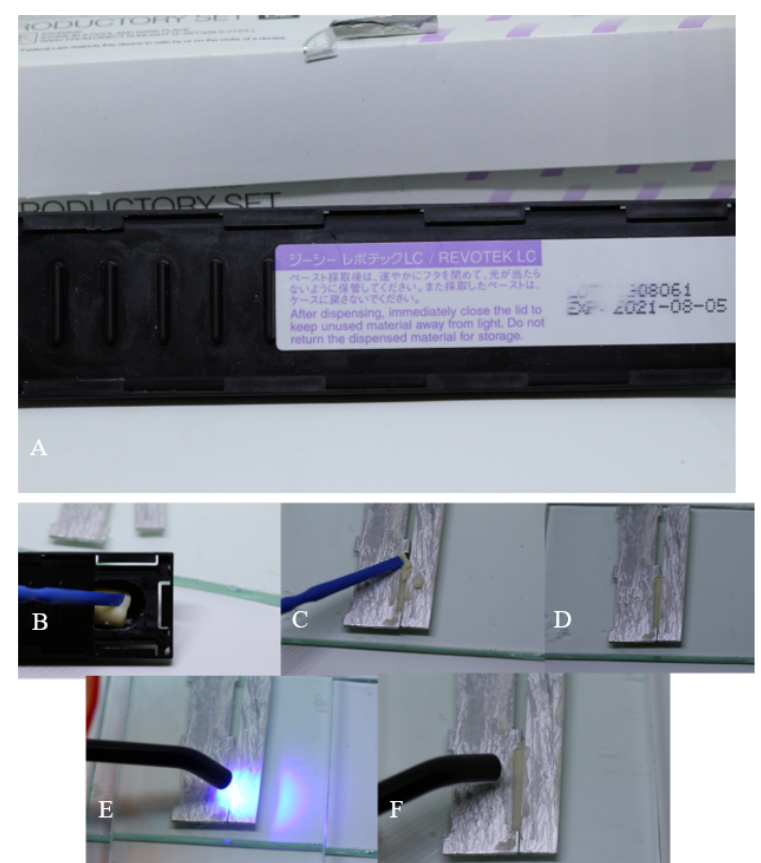

Figure 8: Fabrication of a composite specimen: A: the composite Revoteck LC ${ }^{\circledR}, \mathrm{B}$ : extraction of a small portion of composite, C: insertion of the composite into the mold, D: pressing of the second glass plate, E: Light-curing, F: end result.

\section{The procedure of artificial ageing}

The thermalcycling procedure consisted of a number of thermal cycles that the samples have to undergo. Each cycle consisted of alternating dipping in two containers at $5^{\circ} \mathrm{C}$ and $55^{\circ} \mathrm{C}$ for 30 seconds with a dwell time of 10 seconds in between using the Mechatronik ${ }^{\circledR}$ SD thermal cycler (Figure 9). The samples undergo artificial ageing by Thermo-cycling according to the following table.

\section{Flexural strength test}

Excess materials are eliminated by scraping on sandpaper (grit 2400). The dimensions of the bars are examined by magnifying glass and a precision gauge. The "YLE Universal Testing Machine" (Figure 10 and 11) employed for the testing procedure. The speed of the crosshead is set to $1 \mathrm{~mm} / \mathrm{min}$. 


\begin{tabular}{|l|c|c|c|c|c|}
\hline & $\mathbf{0}$ cycles & $\begin{array}{c}\mathbf{2 5 0 0} \\
\text { cycles }\end{array}$ & $\begin{array}{c}\mathbf{5 0 0 0} \\
\text { cycles }\end{array}$ & $\begin{array}{c}\mathbf{7 5 0 0} \\
\text { cycles }\end{array}$ & $\begin{array}{c}\mathbf{1 0 , 0 0 0} \\
\text { cycles }\end{array}$ \\
\hline Tempsmart & A1 & A2 & A3 & A4 & A5 \\
\hline Cooltemp & B1 & B2 & B3 & B4 & B5 \\
\hline Unifast III & C1 & C2 & C3 & C4 & C5 \\
\hline Revoteck LC & D1 & D2 & D3 & D4 & D5 \\
\hline
\end{tabular}

Treatment of the results

The flexural strength is calculated in MPa as part of the following equations: $\sigma=\frac{3 \mathrm{Fl}}{2 \mathrm{bh}^{2}}$

Where: $\sigma$ is the flexural strength in MPa

$\mathrm{F}$ is the maximum load in Newton.

$l$ is the length, in millimeters.

Table 1: The materials divided by testing groups.

$\mathrm{b}$ is the width in millimeters.

$\mathrm{h}$ is the height in millimeters.

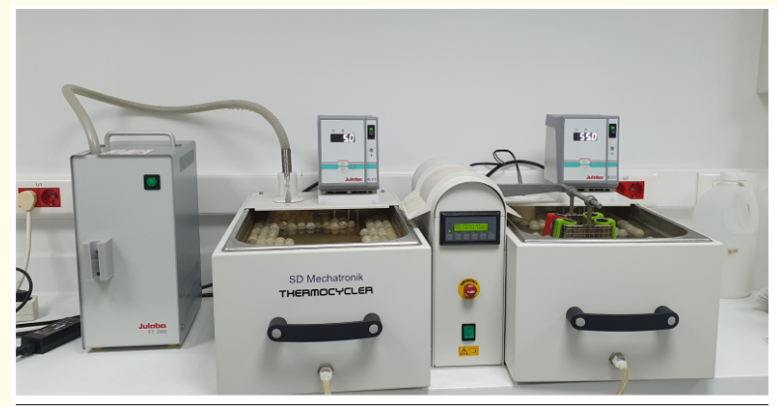

\section{Hypothesis}

The flexural strength of the different materials remains acceptable throughout the period of the study ( $80 \mathrm{MPa}$ according to ISO 4049;2009).

\section{Statistical analysis}

The statistical analyses were performed using IBM SPSS Statistics (version 25.0). The level of significance was set at -p-value $\leq$ 0.05 . The primary outcome variable of this study was the flexural strength in MPa.

Kolmogorov-Smirnov tests and Shapiro-Wilk were used to assess the normal distribution of quantitative variables.

Two-way analysis of variance with two factors (First factor: four provisional materials; second factor: five cycles) was executed to compare the mean flexural strength among groups. Due to statistical interaction, this test was followed by univariate analyses and Bonferroni multiple comparisons tests.

\section{Results}

Normality distribution of primary outcome variable

The normality distribution of the flexural strength in each

Figure 10: Schematic representation of the testing apparatus.

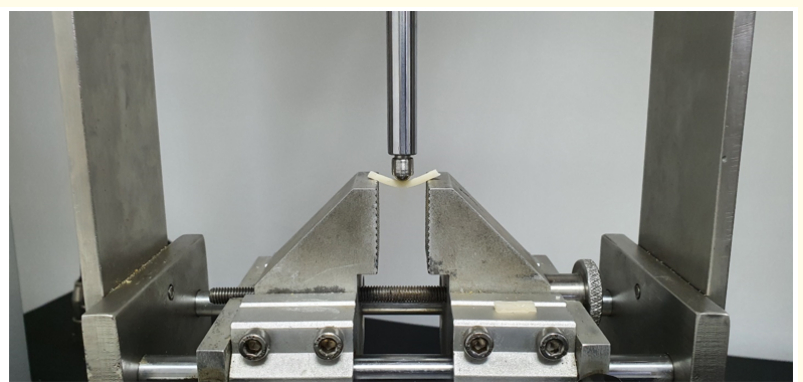

Figure 11: YLE universal testing machine, flexural test mode. group and subgroup is displayed in the following table. The results have shown that the flexural strength is normally distributed for the majority of groups. Parametric tests were therefore used for the statistical comparisons.

\section{Comparison of the mean flexural strength among groups}

The mean, standard-deviation, minimum and maximum values of the flexural strength in different groups are presented in the following table.

\section{Comparison between cycles}

Our findings revealed that:

- The mean flexural strength of Temp Smart was not signifi- 


\begin{tabular}{|c|c|c|c|c|c|c|c|}
\hline \multirow{2}{*}{ Groups } & \multirow{2}{*}{ Cycles } & \multicolumn{3}{|c|}{ Kolmogorov-Smirnov } & \multicolumn{3}{|c|}{ Shapiro-Wilk } \\
\hline & & Statistic & df & p-value & Statistic & df & p-value \\
\hline \multirow{5}{*}{ Temp Smart } & Baseline & 0.213 & 10 & 0.200 & 0.948 & 10 & 0.670 \\
\hline & 2500 cycles & 0.224 & 10 & 0.170 & 0.894 & 10 & 0.189 \\
\hline & 5000 cycles & 0.119 & 10 & 0.200 & 0.959 & 10 & 0.769 \\
\hline & 7500 cycles & 0.174 & 10 & 0.200 & 0.918 & 10 & 0.341 \\
\hline & 10000 cycles & 0.197 & 10 & 0.200 & 0.885 & 10 & 0.148 \\
\hline \multirow{5}{*}{ Cool Temp } & Baseline & 0.186 & 10 & 0.200 & 0.920 & 10 & 0.360 \\
\hline & 2500 cycles & 0.240 & 10 & 0.106 & 0.897 & 10 & 0.202 \\
\hline & 5000 cycles & 0.238 & 10 & 0.115 & 0.915 & 10 & 0.338 \\
\hline & 7500 cycles & 0.169 & 10 & 0.200 & 0.899 & 10 & 0.215 \\
\hline & 10000 cycles & 0.218 & 10 & 0.195 & 0.945 & 10 & 0.612 \\
\hline \multirow{5}{*}{ Unifast III } & Baseline & 0.111 & 10 & 0.200 & 0.950 & 10 & 0.672 \\
\hline & 2500 cycles & 0.220 & 10 & 0.185 & 0.892 & 10 & 0.177 \\
\hline & 5000 cycles & 0.176 & 10 & 0.200 & 0.929 & 10 & 0.433 \\
\hline & 7500 cycles & 0.256 & 10 & 0.062 & 0.916 & 10 & 0.327 \\
\hline & 10000 cycles & 0.260 & 10 & 0.053 & 0.850 & 10 & 0.059 \\
\hline \multirow{5}{*}{ Revoteck LC } & Baseline & 0.323 & 10 & 0.004 & 0.781 & 10 & 0.008 \\
\hline & 2500 cycles & 0.162 & 10 & 0.200 & 0.955 & 10 & 0.732 \\
\hline & 5000 cycles & 0.152 & 10 & 0.200 & 0.936 & 10 & 0.508 \\
\hline & 7500 cycles & 0.202 & 10 & 0.200 & 0.878 & 10 & 0.124 \\
\hline & 10000 cycles & 0.144 & 10 & 0.200 & 0.959 & 10 & 0.778 \\
\hline
\end{tabular}

Table 2: Normality distribution of the flexural strength. df: Degree of Freedom.

\begin{tabular}{|l|c|c|c|c|c|c|}
\hline & N & Minimum & Maximum & Mean & $\begin{array}{c}\text { Std. } \\
\text { Deviation }\end{array}$ & p-value \\
\hline Temp Smart & & & & & & \\
\hline Baseline & 10 & 103.1 & 182.8 & 126.094 & 23.432 & 0.637 \\
\hline 2500 cycles & 10 & 95.5 & 147.9 & 119.894 & 20.260 & \\
\hline 5000 cycles & 10 & 89.1 & 145.8 & 116.618 & 19.541 & \\
\hline 7500 cycles & 10 & 82.3 & 151.4 & 113.580 & 25.513 & \\
\hline 10000 cycles & 10 & 64.8 & 149.8 & 109.734 & 32.363 & \\
\hline Cool Temp & & & & & & \\
\hline Baseline & 10 & 98.4 & 135.9 & 116.250 & 13.035 & 0.617 \\
\hline 2500 cycles & 10 & 59.9 & 140.9 & 109.880 & 27.471 & \\
\hline 5000 cycles & 10 & 70.3 & 117.2 & 106.406 & 14.831 & \\
\hline 7500 cycles & 10 & 74.0 & 162.0 & 103.893 & 25.786 & \\
\hline
\end{tabular}




\begin{tabular}{|l|c|c|c|c|c|c|}
\hline 10000 cycles & 10 & 48.6 & 145.8 & 101.231 & 26.927 & \\
\hline Unifast III & & & & & & \\
\hline Baseline & 10 & 70.3 & 164.1 & 118.125 & 32.760 & 0.223 \\
\hline 2500 cycles & 10 & 68.8 & 170.1 & 106.090 & 29.062 & \\
\hline 5000 cycles & 10 & 56.7 & 129.6 & 98.611 & 24.830 & \\
\hline 7500 cycles & 10 & 45.8 & 137.3 & 95.088 & 26.302 & \\
\hline 10000 cycles & 10 & 64.8 & 129.6 & 91.108 & 24.464 & \\
\hline Revoteck LC & & & & & & \\
\hline Baseline & 10 & 37.5 & 84.4 & $69.375^{\mathrm{c}}$ & 16.358 & 0.000 \\
\hline 2500 cycles & 10 & 32.8 & 79.7 & $52.500^{\mathrm{b}}$ & 13.221 & \\
\hline 5000 cycles & 10 & 35.2 & 63.4 & $46.840^{\mathrm{a}, \mathrm{b}}$ & 8.793 & \\
\hline 7500 cycles & 10 & 35.2 & 45.8 & $41.205^{\mathrm{a}, \mathrm{b}}$ & 4.084 & \\
\hline 10000 cycles & 10 & 12.1 & 52.6 & $36.443^{\mathrm{a}}$ & 12.371 & \\
\hline
\end{tabular}

Table 3: Mean flexural strength in different groups.

a,b,c: Different letters indicate the presence of a significant difference according to multiple comparisons tests.

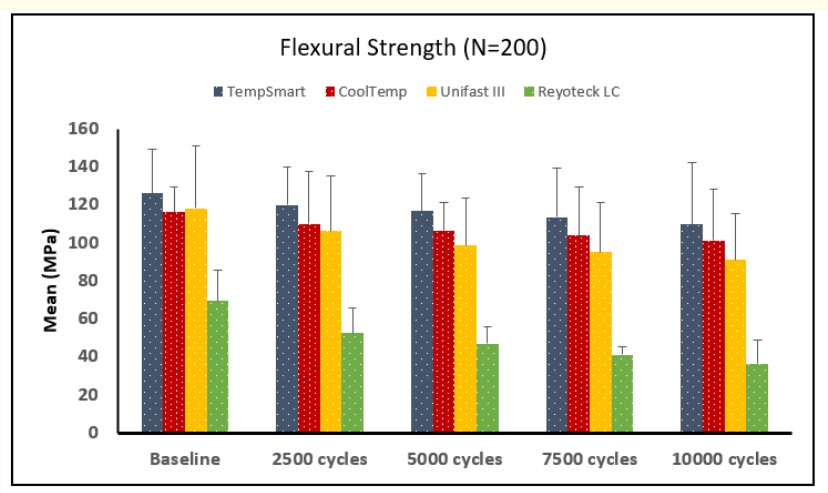

Figure 12: Mean flexural strength among groups.

cantly different among cycles (-p-value $=0.637)$.

- The mean flexural strength of Cool Temp was not significantly different among cycles $(-p$-value $=0.617)$.

- The mean flexural strength of Unifast III has decreased among cycles but the decline was not statistically significant $(-\mathrm{p}$-value $=0.223)$.

- However, the mean flexural strength of Revoteck LC was significantly different among cycles (-p-value $<0.001)$; it de- creased significantly between Baseline and 2500 cycles (-pvalue $=0.020$ ). It also decreased significantly and gradually between 2500 cycles and 10000 cycles (-p-value $=0.029$ ). Baseline $>2500$ cycles $>5000$ cycles $=7500$ cycles $>10000$ cycles.

Comparison between provisional materials

Our study showed:

- At baseline, the mean flexural strength was significantly different among materials groups (-p-value $<0.001)$; it was significantly smaller with Revoteck LC (-p-value $<0.001)$ and the difference was not significant between Temp Smart, Cool Smart and Unifast III (-p-value $=1.000)$.

- After 2500 cycles, the mean flexural strength was significantly different among materials groups (-p-value $<0.001)$; it was significantly smaller with Revoteck LC (-p-value < 0.001) however, we did not find a significant difference between Temp Smart, Cool Smart and Unifast III (-p-value = 1.000).

- After 5000 cycles, the mean flexural strength was significantly different among materials groups (-p-value $<0.001)$; it was significantly smaller with Revoteck LC (-p-value < 0.001 ) but the difference was not significant between Temp 


\begin{tabular}{|c|c|c|c|c|c|c|}
\hline \multirow{2}{*}{ Group } & \multirow{2}{*}{ (I) Cycles } & \multirow{2}{*}{ (J) Cycles } & \multirow{2}{*}{$\begin{array}{c}\text { Mean Difference } \\
(\mathrm{I}-\mathrm{J})\end{array}$} & \multirow{2}{*}{ p-value } & \multicolumn{2}{|c|}{ 95\% Confidence Interval for Difference } \\
\hline & & & & & Lower Bound & Upper Bound \\
\hline \multirow{20}{*}{ Revoteck LC } & \multirow{4}{*}{ Baseline } & 2500 cycles & 16.875 & .020 & 1.954 & 31.796 \\
\hline & & 5000 cycles & 22.535 & .001 & 7.614 & 37.457 \\
\hline & & 7500 cycles & 28.170 & .000 & 13.249 & 43.091 \\
\hline & & 10000 cycles & 32.932 & .000 & 18.011 & 47.853 \\
\hline & \multirow{4}{*}{2500 cycles } & Baseline & -16.875 & .020 & -31.796 & -1.954 \\
\hline & & 5000 cycles & 5.660 & .817 & -9.261 & 20.582 \\
\hline & & 7500 cycles & 11.295 & .217 & -3.626 & 26.216 \\
\hline & & 10000 cycles & 16.057 & .029 & 1.136 & 30.978 \\
\hline & \multirow{4}{*}{5000 cycles } & Baseline & -22.535 & .001 & -37.457 & -7.614 \\
\hline & & 2500 cycles & -5.660 & .817 & -20.582 & 9.261 \\
\hline & & 7500 cycles & 5.635 & .819 & -9.286 & 20.556 \\
\hline & & 10000 cycles & 10.397 & .292 & -4.525 & 25.318 \\
\hline & \multirow{4}{*}{7500 cycles } & Baseline & -28.170 & .000 & -43.091 & -13.249 \\
\hline & & 2500 cycles & -11.295 & .217 & -26.216 & 3.626 \\
\hline & & 5000 cycles & -5.635 & .819 & -20.556 & 9.286 \\
\hline & & 10000 cycles & 4.762 & .893 & -10.160 & 19.683 \\
\hline & \multirow{4}{*}{$\begin{array}{l}10000 \\
\text { cycles }\end{array}$} & Baseline & -32.932 & .000 & -47.853 & -18.011 \\
\hline & & 2500 cycles & -16.057 & .029 & -30.978 & -1.136 \\
\hline & & 5000 cycles & -10.397 & .292 & -25.318 & 4.525 \\
\hline & & 7500 cycles & -4.762 & .893 & -19.683 & 10.160 \\
\hline
\end{tabular}

Table 4: Multiple comparisons tests of the flexural strength between cycles in Revoteck LC group.

\begin{tabular}{|c|c|c|c|c|c|c|}
\hline \multicolumn{2}{|c|}{ Groups } & \multirow{2}{*}{\begin{tabular}{|c|} 
Sum of \\
Squares
\end{tabular}} & \multirow{2}{*}{ Df } & \multirow{2}{*}{$\begin{array}{c}\text { Mean } \\
\text { Square } \\
388.830\end{array}$} & \multirow{2}{*}{$\begin{array}{c}\mathbf{F} \\
0.640\end{array}$} & \multirow{2}{*}{$\frac{\text {-p-value }}{0.637}$} \\
\hline Temp & Contrast & & & & & \\
\hline Smart & Error & 27357.071 & 45 & 607.935 & & \\
\hline \multirow{2}{*}{$\begin{array}{l}\text { Cool } \\
\text { Temp }\end{array}$} & Contrast & 1357.301 & 4 & 339.325 & 0.669 & 0.617 \\
\hline & Error & 22811.096 & 45 & 506.913 & & \\
\hline \multirow{2}{*}{$\begin{array}{l}\text { Unifast } \\
\text { III }\end{array}$} & Contrast & 4544.469 & 4 & 1136.117 & 1.485 & 0.223 \\
\hline & Error & 34421.533 & 45 & 764.923 & & \\
\hline \multirow{2}{*}{$\begin{array}{l}\text { Revo- } \\
\text { teck } \\
\text { LC }\end{array}$} & Contrast & 6501.235 & 4 & 1625.309 & 11.788 & 0.000 \\
\hline & Error & 6204.621 & 45 & 137.880 & & \\
\hline \multicolumn{7}{|c|}{$\begin{array}{l}\text { The F tests the effect of Cycles. This test is based on the linearly } \\
\text { independent pairwise comparisons among the estimated mar- } \\
\text { ginal means. }\end{array}$} \\
\hline
\end{tabular}

Table 5: Univariate analyses of the comparison between cycles in each group.
Smart, Cool Smart and Unifast III (-p-value > 0.05).

- After 7500 cycles, the mean flexural strength was significantly different among materials groups (-p-value $<0.001)$; it was significantly smaller with Revoteck LC (-p-value < 0.001 ) and the difference was not significant between Temp Smart, Cool Smart and Unifast III (-p-value > 0.05).

- After 10000 cycles, the mean flexural strength was significantly different among materials groups (-p-value $<0.001)$; it was significantly less important with Revoteck LC (-p-value $<0.001$ ) and the difference was not significant between Temp Smart, Cool Smart and Unifast III (-p-value > 0.05).

\section{Discussion}

The crucial role of the physical properties of dental materials in achieving the overall goal of temporary restorations was long stated by Donovan., et al. 


\begin{tabular}{|c|c|c|c|c|c|c|}
\hline \multicolumn{2}{|l|}{ Cycles } & \multirow{2}{*}{$\begin{array}{c}\begin{array}{c}\text { Sum of } \\
\text { Squares }\end{array} \\
19886.902 \\
\end{array}$} & \multirow{2}{*}{$\begin{array}{c}\text { Df } \\
3 \\
\end{array}$} & \multirow{2}{*}{$\begin{array}{c}\text { Mean } \\
\text { Square }\end{array}$} & \multirow{2}{*}{$\begin{array}{c}\mathbf{F} \\
12.873 \\
\end{array}$} & \multirow{2}{*}{\begin{tabular}{|c|}
$\begin{array}{c}-\mathbf{p}- \\
\text { value }\end{array}$ \\
.000 \\
\end{tabular}} \\
\hline Base- & Contrast & & & & & \\
\hline line & Error & 18538.330 & 36 & 514.954 & & \\
\hline 2500 & Contrast & 27528.691 & 3 & 9176.230 & 16.802 & .000 \\
\hline cycles & Error & 19660.772 & 36 & 546.133 & & \\
\hline 5000 & Contrast & 28966.874 & 3 & 9655.625 & 29.810 & .000 \\
\hline cycles & Error & 11660.731 & 36 & 323.909 & & \\
\hline 7500 & Contrast & 31461.718 & 3 & 10487.239 & 20.722 & .000 \\
\hline cycles & Error & 18219.007 & 36 & 506.084 & & \\
\hline 10000 & Contrast & 32697.570 & 3 & 10899.190 & 17.273 & .000 \\
\hline cycles & Error & 22715.482 & 36 & 630.986 & & \\
\hline
\end{tabular}

Table 6: Univariate analyses of the comparison of the flexural strength between materials for each cycle.
The flexural strength test remains one of the most preferred testing methods, as it proves advantageous by measuring a wide range of mechanical stresses including tensile and compressive stresses. Contrary to fracture toughness, flexural strength has a strong correlation to the clinical aspect of material wear and is a reliable indicator of it.

The ISO 4049:2009, according to which this study was conducted, provides the extensive and necessary guidelines to allow this type of testing to be conducted in a simple and reproductible manner.

The characteristics of the material

Bis-acrylic temporary restorative materials have been able to surpass the mechanical capacities of the conventional polymerbased temporary materials. The filler content influences the mechanical performance, specifically the flexural strength and the properties related to it. According to Wool., et al. simply adding

\begin{tabular}{|c|c|c|c|c|c|c|}
\hline \multirow{2}{*}{ Cycles } & \multirow{2}{*}{ (I) Groups } & \multirow{2}{*}{ (J) Groups } & \multirow{2}{*}{$\begin{array}{c}\text { Mean } \\
\text { Difference }\end{array}$} & \multirow{2}{*}{-p-value } & \multicolumn{2}{|c|}{ 95\% Confidence Interval for Difference } \\
\hline & & & & & Lower Bound & Upper Bound \\
\hline \multirow{9}{*}{ Baseline } & \multirow{3}{*}{ Temp Smart } & Cool Temp & 9.844 & 1.000 & -18.490 & 38.178 \\
\hline & & Unifast III & 7.969 & 1.000 & -20.365 & 36.303 \\
\hline & & Revoteck LC & 56.719 & .000 & 28.385 & 85.053 \\
\hline & \multirow{3}{*}{ Cool Temp } & Temp Smart & -9.844 & 1.000 & -38.178 & 18.490 \\
\hline & & Unifast III & -1.875 & 1.000 & -30.209 & 26.459 \\
\hline & & Revoteck LC & 46.875 & .000 & 18.541 & 75.209 \\
\hline & \multirow{3}{*}{ Unifast III } & Temp Smart & -7.969 & 1.000 & -36.303 & 20.365 \\
\hline & & Cool Temp & 1.875 & 1.000 & -26.459 & 30.209 \\
\hline & & Revoteck LC & 48.750 & .000 & 20.416 & 77.084 \\
\hline \multirow{9}{*}{$\begin{array}{l}2500 \\
\text { cycles }\end{array}$} & \multirow{3}{*}{ Temp Smart } & Cool Temp & 10.014 & 1.000 & -19.165 & 39.194 \\
\hline & & Unifast III & 13.804 & 1.000 & -15.375 & 42.983 \\
\hline & & Revoteck LC & 67.394 & .000 & 38.215 & 96.573 \\
\hline & \multirow{3}{*}{ Cool Temp } & Temp Smart & -10.014 & 1.000 & -39.194 & 19.165 \\
\hline & & Unifast III & 3.790 & 1.000 & -25.390 & 32.969 \\
\hline & & Revoteck LC & 57.380 & .000 & 28.200 & 86.559 \\
\hline & \multirow{3}{*}{ Unifast III } & Temp Smart & -13.804 & 1.000 & -42.983 & 15.375 \\
\hline & & Cool Temp & -3.790 & 1.000 & -32.969 & 25.390 \\
\hline & & Revoteck LC & 53.590 & .000 & 24.411 & 82.769 \\
\hline
\end{tabular}




\begin{tabular}{|c|c|c|c|c|c|c|}
\hline \multirow{9}{*}{$\begin{array}{l}5000 \\
\text { cycles }\end{array}$} & \multirow{3}{*}{ Temp Smart } & Cool Temp & 10.212 & 1.000 & -12.260 & 32.684 \\
\hline & & Unifast III & 18.007 & .189 & -4.465 & 40.479 \\
\hline & & Revoteck LC & 69.778 & .000 & 47.307 & 92.250 \\
\hline & \multirow{3}{*}{ Cool Temp } & Temp Smart & -10.212 & 1.000 & -32.684 & 12.260 \\
\hline & & Unifast III & 7.795 & 1.000 & -14.677 & 30.267 \\
\hline & & Revoteck LC & 59.566 & .000 & 37.095 & 82.038 \\
\hline & \multirow{3}{*}{ Unifast III } & Temp Smart & -18.007 & .189 & -40.479 & 4.465 \\
\hline & & Cool Temp & -7.795 & 1.000 & -30.267 & 14.677 \\
\hline & & Revoteck LC & 51.771 & .000 & 29.300 & 74.243 \\
\hline \multirow{9}{*}{$\begin{array}{l}7500 \\
\text { cycles }\end{array}$} & \multirow{3}{*}{ Temp Smart } & Cool Temp & 9.687 & 1.000 & -18.402 & 37.777 \\
\hline & & Unifast III & 18.492 & .446 & -9.597 & 46.581 \\
\hline & & Revoteck LC & 72.375 & .000 & 44.286 & 100.464 \\
\hline & \multirow{3}{*}{ Cool Temp } & Temp Smart & -9.687 & 1.000 & -37.777 & 18.402 \\
\hline & & Unifast III & 8.804 & 1.000 & -19.285 & 36.894 \\
\hline & & Revoteck LC & 62.688 & .000 & 34.599 & 90.777 \\
\hline & \multirow{3}{*}{ Unifast III } & Temp Smart & -18.492 & .446 & -46.581 & 9.597 \\
\hline & & Cool Temp & -8.804 & 1.000 & -36.894 & 19.285 \\
\hline & & Revoteck LC & 53.883 & .000 & 25.794 & 81.972 \\
\hline \multirow{9}{*}{$\begin{array}{l}10000 \\
\text { cycles }\end{array}$} & \multirow{3}{*}{ Temp Smart } & Cool Temp & 8.503 & 1.000 & -22.861 & 39.868 \\
\hline & & Unifast III & 18.626 & .636 & -12.738 & 49.991 \\
\hline & & Revoteck LC & 73.291 & .000 & 41.927 & 104.656 \\
\hline & \multirow{3}{*}{ Cool Temp } & Temp Smart & -8.503 & 1.000 & -39.868 & 22.861 \\
\hline & & Unifast III & 10.123 & 1.000 & -21.241 & 41.487 \\
\hline & & Revoteck LC & 64.788 & .000 & 33.424 & 96.152 \\
\hline & \multirow{3}{*}{ Unifast III } & Temp Smart & -18.626 & .636 & -49.991 & 12.738 \\
\hline & & Cool Temp & -10.123 & 1.000 & -41.487 & 21.241 \\
\hline & & Revoteck LC & 54.665 & .000 & 23.300 & 86.029 \\
\hline
\end{tabular}

Table 7: Multiple comparisons tests of the flexural strength between materials for each cycle.

fillers to a polymer matrix system will improve significantly the mechanical performance of a material.

According to Kundie., et al. nanofillers (10 - $40 \mu \mathrm{m})$ improve the flexural strength of a polymer-based material when compared to microfillers (20 - $50 \mathrm{~nm}$ ). The increase of flexural strength can be directly attributed to the following reasons:

1. The nanoparticles help grab monomer and polymer segments.

2. The fillers-matrix chemical bond is strong. The silane coupling agent, present at the surface of the filler, is the key ele- ment for the formation of this bond.

3. The small particle size of the fillers $(10-40 \mu \mathrm{m})$ is responsible for the optimal and homogeneous stress transfer from the soft resin to the nanofillers, through enhanced interfacial adhesion between matrix and nanofiller and the fact that the stress will be shared by a larger number of particles.

4. The increased rigidity and the decreased ductility.

5. The prevention of crack propagation through uniform dispersion. 
The main component

Bis-acryl is a term that can generally mean all the dual-polymerizable temporary crown material. At the molecular level, this term indicates that the chemical composition of the main component is either Bis-GMA or UDMA. In both cases, the component, alone, offers superior mechanical properties than conventional polymethyl methacrylate-based compositions. This is largely due to the higher attainable length of the polymer after polymerization [6].

While Bis-GMA-based temporary materials have emerged first and still occupy an important percentage of the commercially available products, UDMA-based materials, since their inception, have had better results especially while under mechanical testing [7].

In order to simulate the tough conditions a material will have to withstand in the oral cavity, and study more vigorously its properties, several procedures were conducted, putting those materials to the test.

The first element of the process is the aging of the material.

\section{Aging process}

The aging process constitutes a significant part of the study design, as it is meant to simulate the desired intra oral aging process for the predetermined testing period. The most prominent aging techniques are aging by storage and aging by thermocycling (Table of references).

Aging by storage consists of storing the specimens in a fluid (usually distilled water, or artificial saliva) for a predetermined period at $37^{\circ} \mathrm{C}$. The stress is generated when water penetrates the polymer matrix and cause its degradation through the process of hydrolysis [8]. This procedure is time consuming, as it is supposed to match the time window determined in the study design. For example, if the aim of the study is to evaluate the flexural strength of a certain material after 12 months of usage, the specimen would have to be stored in the water or artificial saliva for the same period of 12 months.

Aging by thermocycling, The ISO TR 11450, consists of a determined number of cycles during which the specimens are placed in a high temperature $\left(55^{\circ} \mathrm{C}\right)$ container then a low temperature container $\left(5^{\circ} \mathrm{C}\right)$ for a predetermined number of cycles. This technique presents many advantages over the simple storage technique. First, it is far less time consuming as 10000 cycles, which amounts to about a year in vivo, take approximately 2 weeks to complete. Second, two types of stress are generated: 1) stress by water sorption, and unlike in the case of water storage, the hydrolysis occurs faster and more intensely in the high temperature container, 2) the thermal stress caused by the alternation between the high temperature and the low temperature containers is mirrored by cycles of contraction/expansion stresses in the material at the internal level [9]. Thus, the process of aging by thermocycling offers an alternative to aging by storage that is more potent, quicker and with a higher degree of resemblance to reality.

Aging by occlusal loading (mechanical loading by a chewing simulator), while closely mirroring the chewing forces, only find their usefulness when studying dynamic phenomena in a controlled environment, for example the phenomenon of crack initiation and propagation [10].

\section{Polymerization procedure}

Another factor influencing the mechanical performance, the polymerization method.

Bis-acryl is the only class of material that possesses the dualcuring feature when compared to the conventional acrylic resin is auto-curing, and the resin composite is light-curing. In the most recent experimental study on the subject, the author Akiba, concluded that the specimens have significantly superior flexural strength when a dual-cure approach is applied (chemical curing coupled with light curing) when compared with the self-curing specimens [11].

This is further explained by the evaluation of the degree of conversion, while under the dual curing mode, the resin-based materials have a significantly higher degree of conversion. The higher degree of conversion leads to better structural state of the polymer matrix which evidently results in better physical and mechanical characteristics and a better mechanical performance of the materials.

\section{Results analysis}

In this study, the bis-acrylic products and the conventional PMMA, Tempsmart ${ }^{\circledR}$, Cooltemp ${ }^{\circledR}$ and Unifast III ${ }^{\circledR}$, have performed in a similar way with no significant difference between the results at the baseline or after the aging process. However, the compos- 
ite resin, Revoteck $\mathrm{LC}^{\circledR}$, have shown lower flexural strength values at the baseline, with significant decrease over the many periods of the cycles. The null hypothesis that the flexural strength of the materials will remain acceptable after thermocycling is accepted for the bis-acrylic materials (Tempsmart ${ }^{\circledR}$ and Cooltemp ${ }^{\circledR}$ ) and the conventional PMMA (Unifast III $^{\circledR}$ ) and rejected for the composite material (Revoteck ${ }^{\circledR}$ LC).

\section{Reliability and reproducibility of the study}

Other studies evaluating and implementing similar experimental procedures and conditions have yielded similar results. Thus, providing further evidence surrounding the reproducibility and credibility of the previously established methods.

The mechanical performance of composite-based temporary crown material, Revoteck ${ }^{\circledR}$ LC, was the subject of several studies. The results found in these studies, at the baseline, (58 and 70.37 MPA) [12,13] and after 2500 cycles of thermocycling (60 MPA) [14] are consistent with the values obtained in the present study.

One study conducted the flexural strength test 24 hours after the fabrication process, the mean flexural strength in this case was about 118.1 MPA [15], a slightly lower value than the 126.09 MPA obtained at the baseline. The second study included a more intensive aging process, measuring the flexural strength 24 hours after fabrication, after 5000 and 10000 cycles in the thermocycler, generating respectively the following values: $116.7 \mathrm{MPa}$, 107.7 $\mathrm{MPa}$ and 108.2 MPa [11] which are close values to the ones obtained in the study: $126.09 \mathrm{MPa}, 116.6 \mathrm{MPa}$, and 109.73 MPa.

The second bis-acrylic material, CoolTemp ${ }^{\circledR}$, has not been the subject of any recent studies surrounding the flexural strength, therefore this study proves to be useful for future comparative studies.

The PMMA product, Unifast $\mathrm{III}^{\circledR}$, in this study, has a mean flexural strength of $106.09 \mathrm{MPa}$ at 2500 cycles, significantly different to the results of other studies, coming at $68 \mathrm{MPa}$ [16] and $70 \mathrm{MPa}$ [15] at 2500 cycles. This could be explained by a slight difference in the manipulation of the material during the fabrication of the specimens. Here, the glass plates were compressed by hand for the entire duration of the setting period unlike the other studies where they were held together with a clamp. This difference in pressure during the setting period might have had an influence on the struc- tural integrity of the resin and thus have influenced the outcome of the flexural strength test.

\section{Management of deficiencies}

While the mechanical performance of the materials used in provisional restorations have improved, deficiencies still do occur and often require the practitioner's intervention either through repairing or the making of a new restoration altogether [4].

When using conventional acrylic resin, the procedures of repairing and rebasing can be done through the addition of a small quantity of acrylic resin or a selective addition of flowable composite [17].

The situation differs when it comes to the bis-acrylic resin material. While at first it was thought that repairing a bis-acrylic restoration would result in a less than desirable mechanical performance [18]. However, later studies proved that repairing the fractured bis-acrylic provisional with a flowable composite delivered higher mechanical strength to the point that, while under load, the fracture would most probably occur in the body of the bis-acrylic resin and not in the repaired area [19]. This is where Tempsmart ${ }^{\circledR \prime}$ s composition proves to be remarkably advantageous. This material can be repaired and rebased with the same material, a compatible flowable composite and a conventional polymethyl methacrylate resin.

\section{Strong points of the study}

The design of this study contains several strong points. First, the experimental procedure was largely executed by following closely the standards set by the ISO.

The sample size is significantly large, especially when compared to similar studies.

The aging process is longer than those of all the previous studies. The testing was done after several aging periods. The testing was more frequently than any study on the subject.

The results are in accordance with the findings of similar studies.

\section{Shortcomings of the study}

While the study is focused on materials used in direct technique, it might have been useful to add a heat-cured resin as this 
material has always been one of the first choice materials in long term provisional restoration [1].

The flexural modulus is a second property that could have been explored to add a different level of understanding of the mechanical properties of the tested materials, however, the specific testing machine does not have the proper operating system capable of generating the stress-strain curve. The curve is crucial as its slope is used to calculate the flexural modulus [20].

\section{Conclusion}

Within the limitations of this in vitro study, the bis-acrylic resin materials have displayed the best flexural strength values among the tested materials. The bis-acrylic and polymethylmethacrylate resin materials were adequate all throughout the testing periods while the composite material presented flexural strength values that were insufficient for it to fulfill its purpose as temporary crown material.

The filler content and the long chain formation has given Tempsmart ${ }^{\circledR}$ an advantage from a mechanical point of view over all the other products. And its compatibility with different materials when it comes to repair and modification makes Tempsmart ${ }^{\circledR}$ the most suitable product for clinical applications.

Future studies may complete this experimental study with a broader and larger material to compare and may also test the strength of Tempsmart ${ }^{\circledR}$ when repaired with the wide array of materials it is compatible with.

\section{Bibliography}

1. Burns DR., et al. "A review of selected dental literature on contemporary provisional fixed prosthodontic treatment: report of the Committee on Research in Fixed Prosthodontics of the Academy of Fixed Prosthodontics". Journal of Prosthetic Dentistry 90.5 (2003): 474-497.

2. Luthardt RG., et al. "Clinical performance and periodontal outcome of temporary crowns and fixed partial dentures: A randomized clinical trial". Journal of Prosthetic Dentistry 83.1 (2000): 32-39.

3. Donaldson KJ. "Fundamentals of fixed prosthodontics, fourth edition". The British Dental Journal 213.8 (2012): 427-427.
4. Patras M., et al. "Management of provisional restorations' deficiencies: a literature review". Journal of Esthetic and Restorative Dentistry 24.1 (2012): 26-38.

5. Lang R., et al. "Fracture resistance of PMMA and resin matrix composite-based interim FPD materials". The International Journal of Prosthodontics 16.4 (2003): 381-384.

6. Ogliari FA., et al. "Influence of chain extender length of aromatic dimethacrylates on polymer network development". Dental Materials 24.2 (2008): 165-171.

7. Kerby RE., et al. "Mechanical properties of urethane and bisacryl interim resin materials". Journal of Prosthetic Dentistry 110.1 (2013): 21-28.

8. Guo J-H., et al. "Influence of Physical Aging on Mechanical Properties of Polymer Free Films: The Prediction of Long-Term Aging Effects on the Water Permeability and Dissolution Rate of Polymer Film-Coated Tablets". Pharmaceutical Research 8.12 (1991): 1500-1504.

9. Gale MS and Darvell BW. "Thermal cycling procedures for laboratory testing of dental restorations". Journal of Dentistry 27.2 (1999): 89-99.

10. De Munck J., et al. "A critical review of the durability of adhesion to tooth tissue: methods and results". Journal of Dental Research 84.2 (2005): 118-132.

11. Akiba S., et al. "Influence of different curing modes on flexural properties, fracture toughness, and wear behavior of dualcure provisional resin-based composites". Dental Materials Journal 38.5 (2019): 728-737.

12. Jo LJ., et al. "Flexural strength and hardness of resins for interim fixed partial dentures". Indian Journal of Dental Research Off Publ Indian Journal of Dental Research 22.1 (2011): 71-76.

13. Poonacha V., et al. "In vitro comparison of flexural strength and elastic modulus of three provisional crown materials used in fixed prosthodontics". Journal of Clinical and Experimental Dentistry 5.5 (2013): e212-217.

14. Mehrpour H., et al. "Evaluation of the Flexural Strength of Interim Restorative Materials in Fixed Prosthodontics". Journal of Dentistry 17.3 (2016): 201-206. 
15. Shibasaki S., et al. "Influence of Different Curing Modes on Polymerization Behavior and Mechanical Properties of DualCured Provisional Resins". Operative Dentistry 42.5 (2017): 526-536.

16. Takamizawa T., et al. "Mechanical Properties and Simulated Wear of Provisional Resin Materials". Operative Dentistry 40.6 (2015): 603-613.

17. Wassell RW., et al. "Crowns and other extra-coronal restorations: provisional restorations". The British Dental Journal 192.11 (2002): 619-622.

18. Koumjian JH and Nimmo A. "Evaluation of fracture resistance of resins used for provisional restorations". Journal of Prosthetic Dentistry 64.6 (1990): 654-657.

19. Hagge MS., et al. "Shear bond strength of bis-acryl composite provisional material repaired with flowable composite". Journal of Esthetic and Restorative Dentistry American Academy of Cosmetic Dentistry 14.1 (2002): 47-52.

20. Zweben C., et al. "Test Methods for Fiber Tensile Strength, Composite Flexural Modulus, and Properties of Fabric-Reinforced Laminates". In: Tsai S, editor. Composite Materials: Testing and Design (Fifth Conference). West Conshohocken, PA: ASTM International (1979): 228-262.

\section{Volume 5 Issue 9 September 2021}

(C) All rights are reserved by Georges El Najjar., et al. 